Int. J. Dev. Biol. 58: 65-70 (2014)

doi: $10.1387 / \mathrm{ijdb} .130316 \mathrm{sc}$

\title{
Multiple DIk1 splice variants are expressed during early mouse embryogenesis
}

\author{
ANTONY J. MILLER and SUSAN E. COLE* \\ The Department of Molecular Genetics, The Ohio State University, OH, USA
}

\begin{abstract}
Delta-like homologue 1 (DIk1), an atypical Notch ligand, is known to have roles in growth and development, stem cell maintenance, and cancer. Evidence suggests that Dlk1 expression patterns are more complex than previously appreciated, with multiple isoforms expressed in various tissues in both the embryo and adult. However, the early embryonic expression of Dlk1 has not been well examined. Given that tissue specific DIk1 knockouts have to date failed to recapitulate phenotypes associated with the conventional Dlk1 loss of function model, a better understanding of early DIk1 expression is important. To address this question, we have examined DIk1 expression during the early stages of mouse embryogenesis. Dlk1 expression was first detected at Theiler Stage 14 (TS14), and its expression pattern persisted in specific tissues through TS20. Further, we found that all known DIk1 splice isoforms were expressed in early embryogenesis, with DIk1-A and DIk1-C/C2 isoforms being expressed at the highest levels. The broad co-expression of multiple Dlk1 isoforms corroborates recent work suggesting that Dlk1-mediated signaling may act through multiple DLK1 isoforms to balance differentiation.
\end{abstract}

KEY WORDS: Dlk1, alternative splicing, embryonic expression

Delta-like Homologue 1 (D/k1) is a maternally imprinted gene that encodes a transmembrane protein with homology to the Delta/ Jagged ligands of the mammalian Notch signaling pathway (Smas and Sul, 1993). The DLK1 protein comprises an extracellular domain with a signal peptide and epidermal growth factor (EGF)like repeats, a juxtamembrane region with an isoform-specific TACE-mediated cleavage site, a transmembrane domain, and a small intracellular domain (Smas et al., 1994; Wang et al., 2006; Fig. 1A). DIk1 is alternatively spliced in humans and mice, with transcripts encoding soluble isoforms including TACE cleavage sites, and membrane-bound isoforms lacking the TACE cleavage sites (Smas et al., 1994; Wang et al., 2006; Fig. 1A).

During adipogenesis, soluble DLK1 has been shown to inhibit adipocyte differentiation, while the membrane-bound isoform is thought to promote differentiation (Garcés et al., 1999; Smas and Sul, 1993). In neural stem cells, membrane-bound DLK1 regulates stem cell number in the post-natal subventricular zone via a mechanism that requires soluble DLK1 (Ferrón et al., 2011). Dlk1 has a known role in muscle satellite cell maintenance, and recent work has also suggested differential roles for DLK1 variants during embryonic muscle development (Andersen et al., 2013; Waddell et al., 2010). Taken together, the evidence supports the idea that DIk1 may play significant roles in balancing stem-like behavior with differentiation in a variety of cell types. This may further suggest that the embryonic functions of $D / k 1$ require the regulated expression of multiple DLK1 isoforms, highlighting the importance of alternative mRNA splicing in DIk1-mediated signaling.

DIk1 mRNA distribution has not been studied in early embryogenesis. In late embryogenesis, Dlk1 RNA expression has been reported in the liver, lung, muscle, vertebrae, pancreas, pituitary, and adrenal glands at embryonic day 12.5 (E12.5), and expression is found to be dramatically down-regulated at E16.5 (Yevtodiyenko and Schmidt, 2006). Dlk1 null mice exhibit exhibit growth retardation, skeletal deformations, eyelid abnormalities, and postnatal hypertrophic adipocytes (Moon et al., 2002). In contrast, overexpression of $D / k 1$ via transgene leads to an enhanced growth phenotype, defects in cartilage and bone, and perinatal lethality (Da Rocha et al., 2009). Together, these studies indicate roles for DIk1 in growth and development, with potential functions in tissues known to express Dlk1 at E12.5. However, a recent study made conditional deletions of Dlk1 in several tissues including pituitary somatotrophs, pancreatic beta cells and endothelial cells. None

Abbreviations used in this paper: Dlk1, Delta-like homologue 1; PSM, presomitic mesoderm; TS, Theiler Stage.

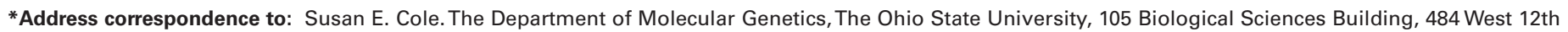
Ave. Columbus, OH 43210, USA.Tel: 614-292-3276. e-mail: cole.354@osu.edu
} 
A

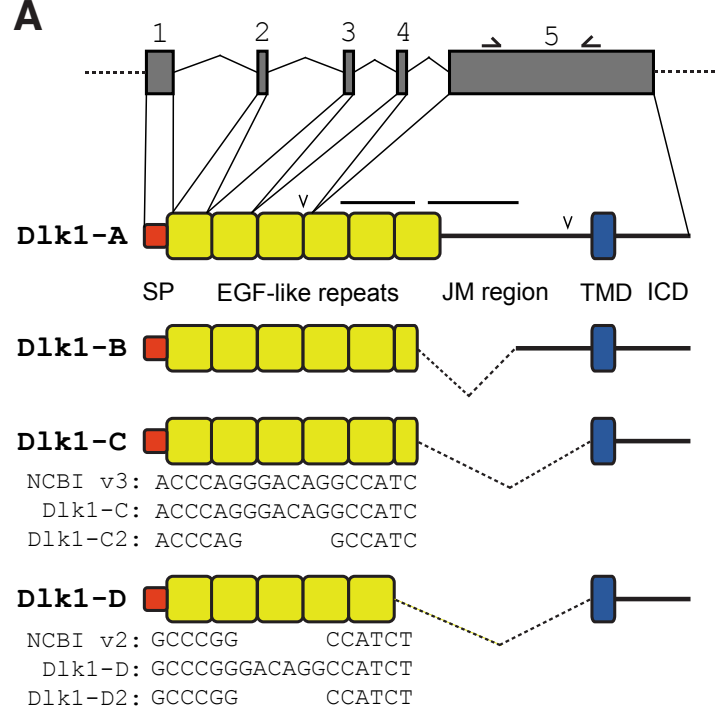

B

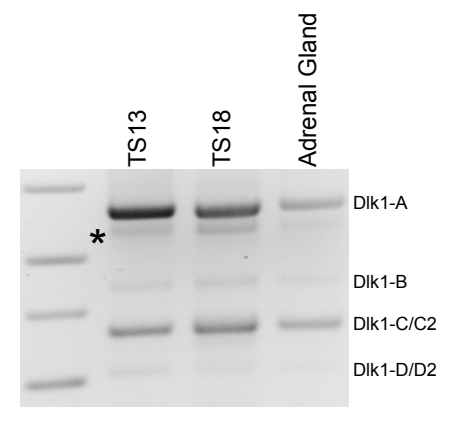

Fig. 1. All known DIk1 isoforms are expressed during early mouse embryogenesis. (A) Schematic of previously described DLK1 protein isoforms. Some DLK1 variants contain potential TACE cleavage sites (arrow heads). All isoforms possess a signal peptide (SP), a varying number of epidermal growth factor (EGF)-like repeats, a transmembrane domain (TMD), and an intercellular domain (ICD). Full-length DLK1 (-A) and DLK1-B encode secreted forms of DLK1 while DLK1-C/ $C 2$ and DLK1-D/D2 encode membrane-bound isoforms. Lines above DLK1-A indicate the positions of in situ probes. The probe on the left detects all Dlk1 transcripts (pan-DIk1 expression), while the right hand probe detects DIk1-A expression. Both DIk1-C and DIk1-D encompass two variants that differ by 6 base pairs. The sequences of Dlk-C (NM_001190704), and Dlk1-D2 (NM_001190703) are shown along with the sequences of D and C2. (B) RT-PCR using primers flanking the alternatively spliced region of Dlk1 (arrows in A) were used to examine the expression of Dlk1 splice variants during early mouse development. All four major variants (Dlk1-A, -B, -C, and -D) and two sub-variants (DIk1-C2 and DIk1-D2) were detected when bands were cloned and sequenced. The unpredicted band of $500 \mathrm{bp}$ (asterisk) was not clonable or sequenceable, and when purified and used as a template for further PCR, it gave rise to several Dlk1 isoforms. We conclude that this band represents a heteroduplex.

of these tissue specific deletions recapitulate the phenotypes of Dlk1 null animals, suggesting that the requirements for Dlk1 during embryogenesis are complex, and that understanding the DIk1 expression pattern during early embryogenesis may give further hints about its functions (Appelbe et al., 2013).

Given these facts, and the finding that DLK1 protein expression can be observed as early as E10 (Falix et al., 2013), we performed a study of DIk1 expression during early mouse embryogenesis. Here, we demonstrate that $D / k 1$ expression is detectable as early as Theiler Stage 13 (TS13, E8.5 on our background). Thus, Dlk1 is expressed during the developmental periods in which terminal differentiation and organogenesis begin to occur in the mouse embryo. Expression patterns at these early stages are tissue specific, with DIk1 expression highest in regions where regulation of cell differentiation is important. Interestingly, we find that all known DIk1 isoforms are expressed during these early stages of embryogenesis, and we find that transcripts encoding the full-length and membrane-bound forms are co-expressed on the whole-tissue level. These results corroborate and extend previous DIk1 expres-
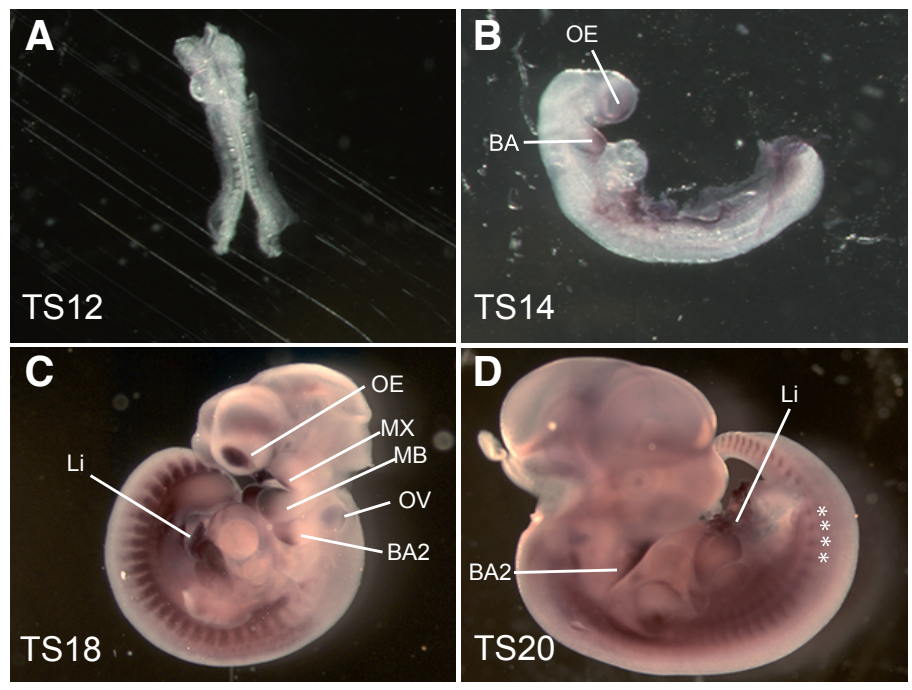

sion studies. Further, this suggests that the tissues utilizing DIk1mediated signaling do so through more than one isoform, possibly to mediate signaling between the stroma and parenchyma within a tissue in a paracrine fashion as has been previously suggested (Andersen et al., 2013; Appelbe et al., 2013).

\section{Results}

\section{All known Dlk1 isoforms are expressed during early mouse embryogenesis}

To determine which Dlk1 isoforms are expressed during early embryogenesis, we examined mouse embryos at TS13 ( E8.5) and TS18 ( E10.5; Fig. 1). Using primers that flank the alternativelyspliced region of $D / k 1$ exon 5 (Fig. 1A), we simultaneously amplified all Dlk1 transcripts (Fig. 1B). PCR products were subcloned, and sequenced, and we find that all six previously identified $D / k 1$ isoforms (A, B, C, C2, D, and D2) are expressed in mouse embryos (Smas et al., 1994; Fig. 1A). An additional PCR product was subsequently determined to be a heteroduplex (Fig. 1B). The highest levels of expression detected at these stages were represented by the DIk1-A and DIk1-C/C2 transcripts, which give rise to secreted and membrane-bound forms of DLK1, respectively (Smas et al., 1997; Yevtodiyenko and Schmidt, 2006; Fig. 1B). These data indicate that all previously described Dlk1 isoforms are expressed during

Fig. 2. Dlk1 expression is initiated at the onset of organogenesis, and is confined to a subset of embryonic tissues. Whole mount in situ hybridization using an RNA probe designed to detect the expression of all Dlk1 isoforms simultaneously (pan-Dlk1 expression) was performed at several developmental stages. (A) No pan-Dlk1 expression is detected at Theiler Stage (TS) 12, which occurs at approximately E8.0 in the mouse. (B) Dlk1 expression is first detected in the branchial arches (BA) and olfactory epithelium (OE) at TS14. (C) At TS18 expression is detected in the mature somites (asterisks), in the liver ( $L i)$, the otic vesicle (OV), the maxillary (MX) and mandibular (MD) processes of the first $B A$, the second $B A(B A 2)$ and in the presomitic mesoderm (PSM; inset). Expression in the OE and BA is detected at higher levels than at previous stages. (D) AtTS20, pan-DIk1 expression is down-regulated in the somites (asterisks), the BA, and Li. 

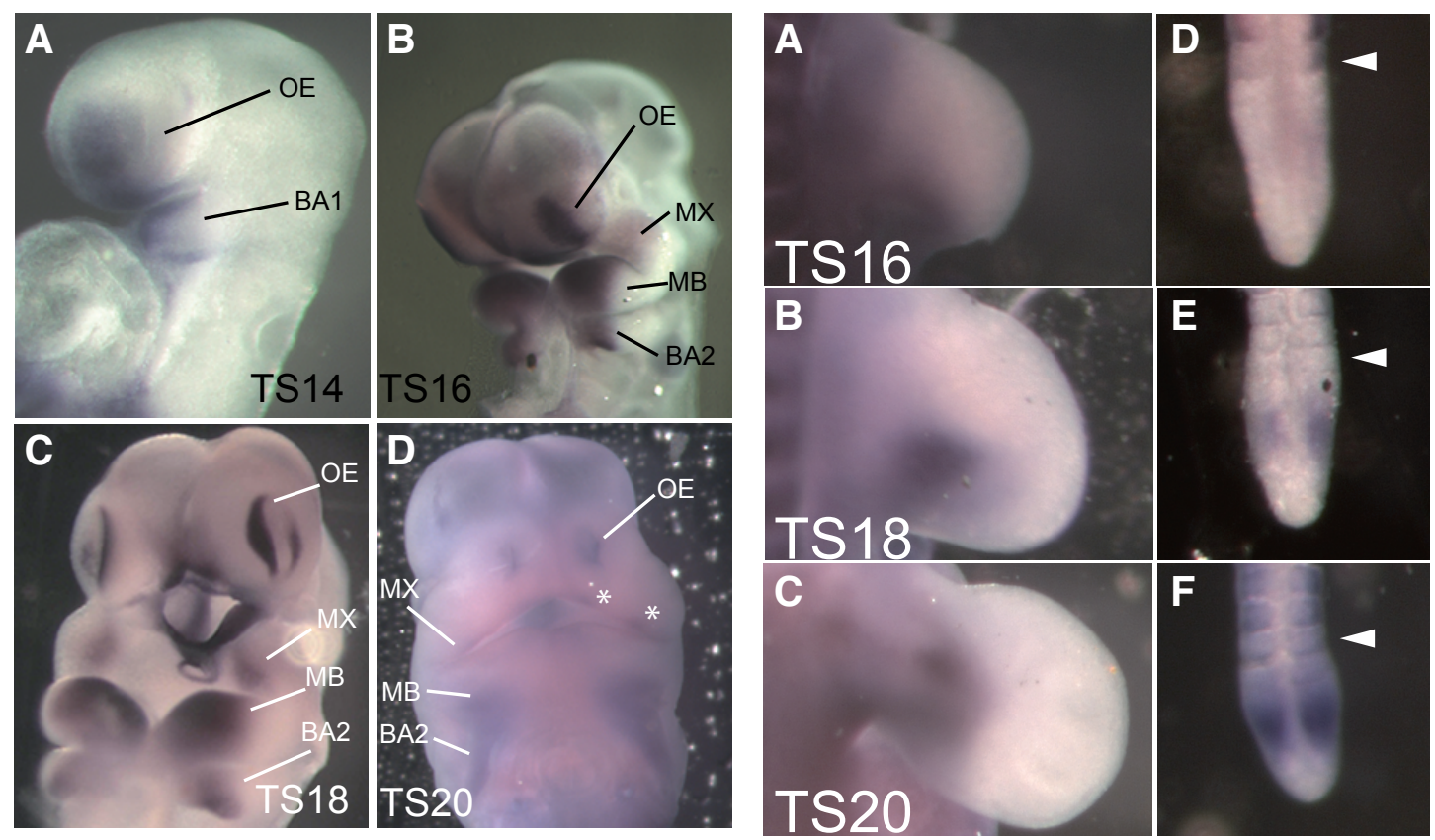

Fig. 3 (Left). DIk1 is expressed in a stage-dependent manner in the olfactory epithelium and branchial arches. Whole mount in situ hybridization analysis of panDlk1 expression in the developing olfactory epithelium and branchial arches was performed throughout the stages of detectable expression. (A) Pan-Dlk1 expression is first detected in the first branchial arch (BA1) and the olfactory epithelium (OE) of the olfactory placodes at TS14. (B) At TS16, as the OE has thickened, Dlk1 expression has intensified markedly. BA1 has bifurcated into the maxillary and mandibular prominences (MX and MB, respectively). Here, pan-DIk1 expression has also intensified. (C) By TS18, pan-DIk1 expression has become restricted to the periphery of the $O E$, with no detectable expression within the invaginating nasal pit. Expression has also become highly restricted in the $M X, M B$ and BA2. (D) Expression in the OE has been reduced, but is still detectable at the periphery of the OE and in MX by TS20. In MB and BA2, expression has also been down-regulated.

Fig. 4. (Right) DIk1 is expressed dynamically in the developing limb buds. Pan-DIk1 in situ hybridization was examined in limb buds and the PSM at various embryonic stages. (A) Pan-Dlk1 is expressed in a restricted pattern near the center of the developing limb bud at TS16, with expression also detectable at the midline. (B) At TS18, the pan-DIk1 expression pattern closely resembles that observed at TS16, though expression has intensified. (C) By TS20, the pan-DIk1 expression pattern is elongated along the ventro-medial axis of the limb bud, and DIk1 expression appears to have been downregulated in this tissue. (D-F) Pan-DIk1 expression in the PSM is first detected after TS16, and appears as a broad stripe near the anterior boundary of the PSM. Expression here is not cyclic, and is detected throughout the developmental period during which somitogenesis occurs (data not shown).

early mouse embryogenesis, and that it is the Dlk1-A and Dlk1-C/ C2 isoforms that predominate at these stages of development.

\section{DIk1 is expressed in a tissue-specific manner during embryogenesis}

Having detected expression of Dlk1 during early embryogenesis, we examined the spatial distribution of DIk1 transcripts during this period of development. In situ hybridization was performed to simultaneously examine the expression pattern of all Dlk 1 isoforms using a probe spanning EGF repeats 4-6, which are shared among all known isoforms (pan-Dlk1 expression; Fig. 2). No expression was observed at TS12 ( E8.0; Fig. 2A). Robust Dlk1 expression is first detected at TS14, in the first branchial arch (BA) and the olfactory epithelium (OE; Fig. 2B). At TS18, expression is also apparent in the liver, limb buds, otic vesicle, and mature somites (Figure 2C). At this stage, expression is strong in both the first and second branchial arch structures, as well as the OE. At TS20, expression has been refined in the $\mathrm{OE}$ and the $\mathrm{BA}$ and is maintained in the liver and somites (Fig. 2D). The expression patterns observed at these early developmental stages are consistent with the previously reported functions of Dlk1, though embryonic expression in the branchial arches and olfactory epithelium has not been previously reported.

\section{DIk1 expression in the branchial arches and olfactory epithelium is robust and specific}

As the first specific site of pan-Dlk1 expression is in the BA and OE at TS14, we examined these structures in more detail throughout early embryogenesis (Fig. 3). Pan-DIk1 expression is detected in the mandibular process of the first BA at TS14 (Fig. 3A). As craniofacial development proceeds, DIk1 expression is evident in the maxillary (MX) and mandibular processes (MD) as well as in the second branchial arch (Fig. 3B). Dlk1 expression is refined as these tissues mature, becoming highly restricted in the $\mathrm{MX}$, and more restricted in the MD and BA2 at TS18 (Fig. 3C). By TS20, Dlk1 expression is downregulated in the craniofacial region, though it can still be observed in distinct puncta in the MX (Fig. 3D; asterisks).

The olfactory placodes are specialized epithelial thickenings that invaginate to form the nasal pit. Pan-DIk1 expression is evident in the olfactory epithelium (OE) of the placode at TS14 (Fig. 3A). Expression in the OE intensifies at TS16 as it thickens (Fig. 3B). Notably, as the placode invaginates at TS18, pan-DIk1 expression becomes restricted to the marginal rim of the OE (Fig. 3C). At TS20, pan-DIk1 expression is again largely extinguished, though the detectable expression remains at the periphery of the OE (Fig. 3D).

\section{DIk1 is expressed in the developing limb buds and presomitic mesoderm (PSM)}

Given the previously suggested roles for Dlk1 in muscle development (Andersen et al., 2013), we further examined the pan-DIk1 expression pattern in the somites, limb buds and PSM. At TS16, Dlk1 expression is robust at the posterior and midline of 
the limb bud (Fig. 4A). At TS18, a condensation of DIk1 expression is detected near the central limb bud (Fig. 4B), and by TS20, pan-DIk1 expression is detected as a stripe at the midline of the limb bud (Fig. 4C). This observation corroborates studies that have found roles for DIk1 in embryonic muscle development and muscle precursor cells (Andersen et al., 2013; Moon et al., 2002; Waddell et al., 2010).

DIk1 has been proposed to function in modulation of the Notch signaling pathway. In the presomitic mesoderm (PSM) oscillatory Notch1 signaling in the PSM is critical for the regulation of the axial skeleton by the segmentation clock. We therefore examined the expression of DIk1 in the PSM to determine whether its expression links it to the clock. Pan-Dlk1 expression in the PSM is only weakly detectable prior to TS16 (Fig. 4D). Robust expression is observed at TS16, with a broad band of DIk1 expression in the posterior PSM (Fig. 4E), that is maintained at TS18 (Fig. 4F). Unlike the expression of some other Notch pathway members, however, expression of DIk1 in the PSM is stable, with no evidence of oscillatory expression $(n=10)$. Thus it is unlikely that Dlk1 plays a significant role in the segmentation clock, despite the occasional observation of rib fusions and other axial skeleton abnormalities in Dlk1 mutant mice (Moon et al., 2002).

\section{Distinct DIk1 isoforms are co-expressed in developing tissues during early embryogenesis}

An in situ probe which will hybridize specifically with the Dlk1-A transcript, while not detecting $D / k 1-B,-C$ or $-D$ (see Fig. 1), was used to compare the specific expression pattern of DIk1-A to the pan-DIk1 expression patterns (Fig. 5). At TS18, we find that the overall expression pattern of DIk1-A is strikingly similar to that of pan-DIk1 (Fig. 5). All tissues observed to express DIk1 were found to express $D / k 1-A$, although the intensity of staining varied somewhat from tissue to tissue. In the mature somites (Fig. 5A and $E$ ) and FLB (Fig. 5B and F), Dlk1-A expression levels seem similar to those detected using the pan-DIk1 probe. However, detection of $D / k 1-A$ was weaker in the PSM (Fig. $5 \mathrm{D}$ and $\mathrm{H}$ ) and during early limb bud development (Fig. 5C and G). However, given the nonquantitative nature of whole mount in situ analysis, it is difficult to ascertain whether these differences represent differential regulation of splicing in these tissues.

As an independent method to examine tissue specific splicing regulation, we examined Dlk1 expression by RT-PCR using RNA extracted from whole embryos, PSMs, hind limb buds, and fore limb bud tissues at TS18 (Fig. 5I). In all tissues, all known DIk1 isoforms were amplified, with the $D I k 1-A$ and $D I k 1-C / C 2$ isoforms exhibiting the highest levels of expression. As observed previously, D/k1-D/D2 is expressed at very low levels in all tissues examined. These data indicate that all $D / k 1$ isoforms are expressed in a variety of tissues at this early stage of development.

\section{Discussion}

The expression patterns described here suggest that DIk1 may have specific functions during early stages of mouse development. DIk1 has a well-documented role in mesenchymal cell fate, and DIk1 function in the PSM may be related to a role in maintaining mesenchymal cells in an immature state prior to differentiation (Sul, 2009; Wang and Sul, 2009). The observed expression in the somites and limb buds could reflect the suggested role for Dlk1 in regulating embryonic muscle development (Andersen et al., 2013; Waddell et al., 2010). Dlk1 has previously been shown to be expressed in hepatoblasts and hepatic stellate precursor cells, thus the observed liver expression is likely indicative of these cell populations (Zhu et al., 2012).

We are the first to report strong expression of DIk 1 in the branchial arches and their derivatives and in the olfactory epithelium. The early and robust expression in the branchial arch mesenchyme
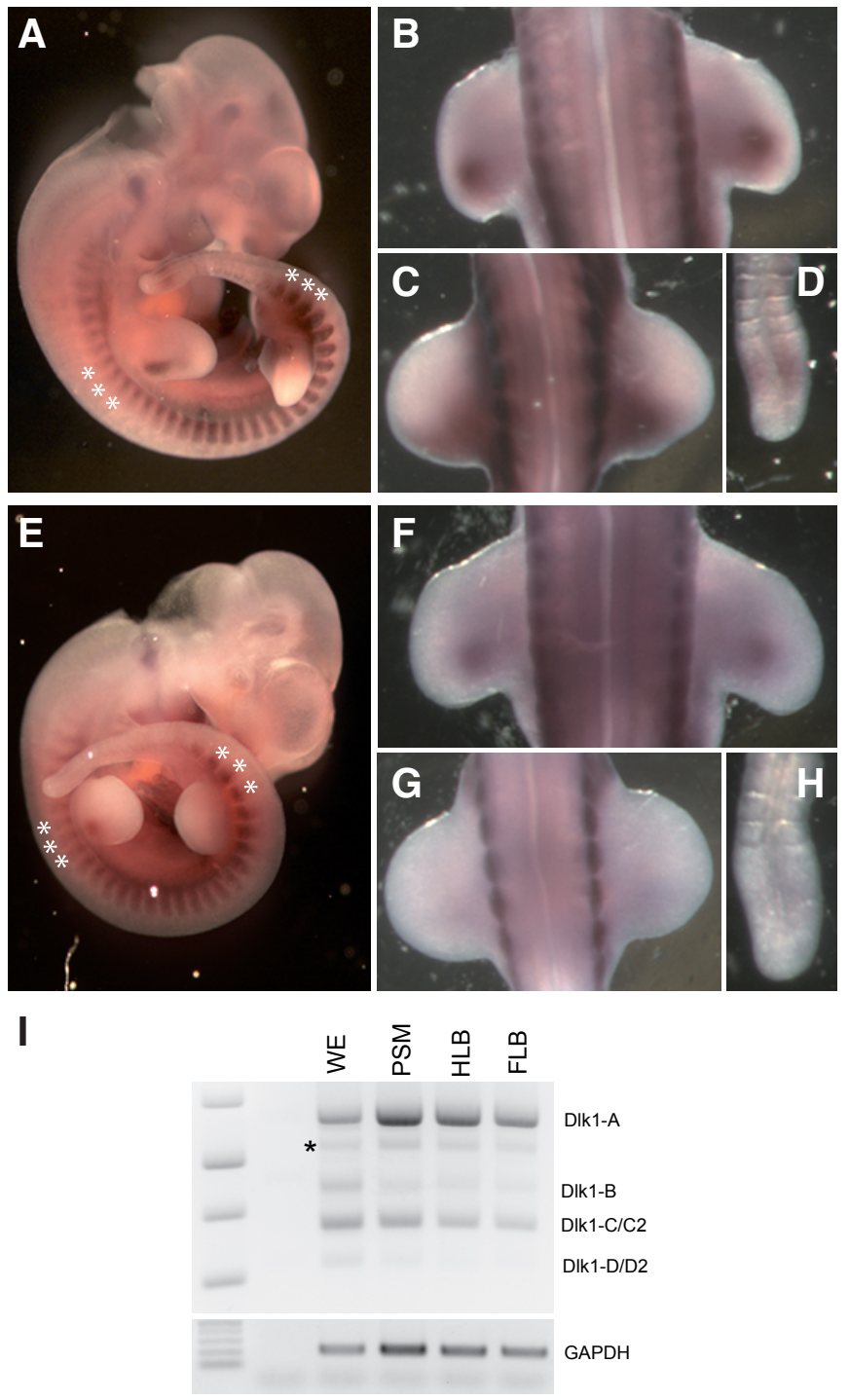

Fig. 5. Soluble and membrane-bound DIk1 isoforms are broadly coexpressed during early development. Pan-Dlk1 in situ hybridization was compared to in situ hybridization using a DIk1-A specific RNA probe (see figure 1). DIk1-A expression is detected at a level similar to that of pan-DIk1 expression in mature somites; see asterisks in $(\mathbf{A}, \mathbf{E})$, and in the forelimb buds (B,F). Differences in levels of expression are detectable in the hind limb buds $(\mathbf{C}, \mathbf{G})$ and in the PSM (D,H), with lower levels of DIk1-A detected relative to detection of pan-DIk1 expression. (I) Expression levels of DIk1 transcripts were analyed by $R T-P C R$ using total reverse-transcribed cDNA extracted from whole embryo (WE), PSM, FLB and HLB tissues at TS18. Pan-DIk1 expression analysis demonstrates similar expression patterns for all Dlk1 transcripts for each of the tissues examined. In all tissues examined, the DIk1-A and DIk1-C/C2 isoforms are detected at the highest levels. 
may reflect functional roles for DIk1 during craniofacial development, while expression of DIk1 at the periphery of the invaginating nasal pit, the domain of olfactory epithelial morphogenesis where olfactory neural stem and progenitor cells reside, is consistent with the described role of DIk1 in neural stem cell maintenance (Ferrón et al., 2011; Kawauchi et al., 2005; Schmidt et al., 2000). In support of this, asymmetric expression of Dlk1 at the peripheral OE is reminiscent of Sox2 expression in this tissue (Chen et al., 2009).

A recent study used section $\mathrm{IHC}$ to detect DLK1 protein expression at similar stages to those reported here (Falix et al., 2013), and identified protein expression in many of the same structures during early embryogenesis. These results are complementary, as together these studies allow us to assess both protein and RNA expression in embryonic sections as well as in whole mounts. The data reported here identify additional sites of expression, and shed light on the control of transcript splicing, which is not possible using antibody analysis. Together, these findings allow us to assess the effects of transcriptional, post transcriptional and post-translational control of Dlk1 in the early embryo.

Our RT-PCR results demonstrate that DIk1 splice variants encoding both membrane bound and secreted versions of the DLK1 protein are co-expressed in an array of developmentally distinct tissues. The fact that in all tissues examined $D I k 1-A$ (secreted) and DIk1-C/C2 (membrane bound) are expressed at the highest levels, indicates that both forms of the protein are functional during early embryonic development. Further examination will be needed to determine whether individual cells within the developing tissues may express specific Dlk1 isoforms.

In summary, we have demonstrated for the first time that all known Dlk1 isoforms are expressed during early embryogenesis. We find that DIk1 expression patterns can be correlated with previous in vitro and tissue-specific functional studies, and expression studies at later developmental stages. We have also described for the first time expression of DIk1 in the branchial arches and the olfactory epithelium. Finally, we have found that soluble and membrane-bound Dlk1 isoforms are broadly co-expressed during early embryonic development, with both membrane bound and secreted isoforms being found in similar embryonic tissues. In light of previous work studying the functions of the DLK1 splice variants (Garcés et al., 1999), this suggests that both DLK1 variants have roles in organogenesis.

\section{Materials and Methods}

\section{Timed pregnancy and embryo collection}

Embryos were collected from timed pregnancies of FVB/NJ mice, with noon the day of plug identification designated as 0.5 d.p.c. Embryos were further staged according to Theiler. On this background, TS12 was $\sim 8.0$ d.p.c., TS14 was $\sim 8.5$ d.p.c., TS16 was $\sim 9.5$ d.p.c., TS18 was $\sim 10.5$ d.p.c., and TS20 was $\sim 11.5$ d.p.c. All mice were maintained under the care of the Ohio State University IACUC.

\section{In situ hybridization}

RNA is situ hybridization using digoxygenin-labeled probes was performed using standard protocols (Shifley and Cole, 2008). For simultaneous detection of all Dlk1 transcripts (pan-Dlk1 expression), a $382 \mathrm{bp}$ fragment of the cDNA, was amplified by RT-PCR using primers SC-628 (5'-tgtcaatggagtctgcaagg-3') and SC-629: (5'-atcgttctcgcatgggttag-3'). For specific detection of $D / k 1-A$, a $185 \mathrm{bp}$ fragment, corresponding to the intron of the DIk1-B isoform was amplified by RT-PCR using the primers: SC690 (5'-tgagcttcgagtgtctgtgc-3') and SC-691 (5'-tttcatggacaccttcagga-3').

\section{$R T-P C R$}

Total poly $(A)^{+}$-selected RNA was extracted from dissected embryos and first strand cDNA synthesis was completed (SuperScript III, Invitrogen). All DIk1 transcripts were amplified simultaneously using the primers SC-655 (5'-cacctgggttctctggaaag-3') and SC-656 (5'-acgcccaggatggtgaag-3'), which yields predicted bands corresponding to $D / k 1-A$ at $595 \mathrm{bp}, D / k 1-B$ at 442 bp, DIk1-C/C2 at $376 \mathrm{bp}$, and DIk1-D/D2 at $310 \mathrm{bp}$.

\section{Acknowledgements}

We thank the members of the Cole lab for helpful discussions. This work was supported in part by NSF grant \# IOS-0919649 to SEC.

\section{References}

ANDERSEN, D.C., LABORDA, J., BALADRON, V., KASSEM, M., SHEIKH, S.P., and JENSEN, C.H. (2013). Dual role of delta-like 1 homolog (DLK1) in skeletal muscle development and adult muscle regeneration. Development 140: 3743-3753.

APPELBE, O.K., YEVTODIYENKO, A., MUNIZ-TALAVERA, H., and SCHMIDT, J.V. (2013). Conditional deletions refine the embryonic requirement for Dlk1. Mech Dev 130: 143-159.

CHEN, B., KIM, E.-H., and XU, P.-X. (2009). Initiation of olfactory placode development and neurogenesis is blocked in mice lacking both Six1 and Six4. Mech Dev 326: 75-85.

DAROCHA, S.T., CHARALAMBOUS, M., LIN, S.-P., GUTTERIDGE, I., ITO, Y., GRAY, D., DEAN, W., and FERGUSON-SMITH, A.C. (2009). Gene Dosage Effects of the Imprinted Delta-Like Homologue 1 (DIk1/Pref1) in Development: Implications for the Evolution of Imprinting. PLoS Genet 5: e1000392.

FALIX, F.A., TJON-A-LOI, M.R.S., GAEMERS, I.C., ARONSON, D.C., and LAMERS, W.H. (2013). DLK1 Protein Expression during Mouse Development Provides New Insights into Its Function. ISRN Dev Biol 2013: 1-10.

FERRÓN, S.R., CHARALAMBOUS, M., RADFORD, E., MCEWEN, K., WILDNER, H., HIND, E., MORANTE-REDOLAT, J.M., LABORDA, J., GUILLEMOT, F., BAUER, S.R., et al., (2011). Postnatal loss of Dlk1 imprinting in stem cells and niche astrocytes regulates neurogenesis. Nature 475: 381-385

GARCÉS, C., GARCES, C., RUIZ-HIDALGO, M.J., BONVINI, E., GOLDSTEIN, J., LABORDA, J., RUIZ-HIDALGO, M.J., and LABORDA, J. (1999). Adipocyte differentiation is modulated by secreted delta-like (dlk) variants and requires the expression of membrane-associated dlk. Differentiation 64: 103-114.

KAWAUCHI, S., SHOU, J., SANTOS, R., HÉBERT, J.M., MCCONNELL, S.K., MASON, I., and CALOF, A.L. (2005). Fgf8 expression defines a morphogenetic center required for olfactory neurogenesis and nasal cavity development in the mouse. Development 132: 5211-5223.

MOON, Y.S., SMAS, C.M., LEE, K., VILLENA, J.A., KIM, K.H., YUN, E.J., and SUL, H.S. (2002). Mice Lacking Paternally Expressed Pref-1/Dlk1 Display Growth Retardation and Accelerated Adiposity. Mol Cell Biol 22: 5585-5592.

SCHMIDT, J.V., MATTESON, P.G., JONES, B.K., GUAN, X.-J., and TILGHMAN, S.M. (2000). The Dlk1 and Gtl2 genes are linked and reciprocally imprinted. Genes Dev 14: 1997-2002.

SHIFLEY, E.T., and COLE, S.E. (2008). Lunatic fringe protein processing by proprotein convertases may contribute to the short protein half-life in the segmentation clock. BBA-Mol. Cell Res. 1783: 2384-2390.

SMAS, C.M., CHEN, L., and SUL, H.S. (1997). Cleavage of membrane-associated pref-1 generates a soluble inhibitor of adipocyte differentiation. Mol Cell Biol 17: 977-988.

SMAS, C.M., GREEN, D., and SUL, H.S. (1994). Structural characterization and alternate splicing of the gene encoding the preadipocyte EGF-like protein pref-1. Biochemistry 33: 9257-9265.

SMAS, C., and SUL, H. (1993). Pref-1, a protein containing EGF-like repeats, inhibits adipocyte differentiation. Cell 73: 725-734.

SUL, H.S. (2009). Minireview: Pref-1: role in adipogenesis and mesenchymal cell fate. Mol Endocrinol 23: 1717-1725.

WADDELL, J.N., ZHANG, P., WEN, Y., GUPTA, S.K., YEVTODIYENKO, A., SCHMIDT, J.V., BIDWELL, C.A., KUMAR, A., and KUANG, S. (2010). Dlk1 is necessary for proper skeletal muscle development and regeneration. PLOS ONE 5: e15055e15055. 
WANG, H., WANG, Y., SUL, H., WANG, Y., and SUL, H. (2006). Ectodomain Shedding of Preadipocyte Factor 1 (Pref-1) by Tumor Necrosis Factor Alpha Converting Enzyme (TACE) and Inhibition of Adipocyte Differentiation. Mol Cell Biol 26: 5421-5435.

WANG, Y., and SUL, H.S. (2009). Pref-1 Regulates Mesenchymal Cell Commitment and Differentiation through Sox9. Cell Metab 9: 287-302.
YEVTODIYENKO, A., and SCHMIDT, J.V. (2006). Dlk1 expression marks developing endothelium and sites of branching morphogenesis in the mouse embryo and placenta. Dev Dyn 235: 1115-1123.

ZHU, N.L., ASAHINA, K., WANG, J., UENO, A., LAZARO, R., MIYAOKA, Y., MIYAJIMA, A., and TSUKAMOTO, H. (2012). Hepatic Stellate Cell-derived Delta-like Homolog 1 (DLK1) Protein in Liver Regeneration. J Biol Chem 287: 10355-10367. 


\section{Further Related Reading, published previously in the Int. J. Dev. Biol.}

\section{Lateral inhibition and neurogenesis: novel aspects in motion}

Pau Formosa-Jordan, Marta Ibañes, Saúl Ares and José-María Frade

Int. J. Dev. Biol. (2013) 57: 341-350

http://dx.doi.org/10.1387/ijdb.120259jf

Genome-wide gene expression analysis in mouse embryonic stem cells Juan Sainz, Fernando García-Alcalde, Armando Blanco and Ángel Concha Int. J. Dev. Biol. (2011) 55: 995-1006

http://dx.doi.org/10.1387/ijdb.103123js

Six1 is indispensable for production of functional progenitor cells during olfactory epithelial development

Keiko Ikeda, Ryoichiro Kageyama, Yuko Suzuki and Kiyoshi Kawakami

Int. J. Dev. Biol. (2010) 54: 1453-1464

http://dx.doi.org/10.1387/ijdb.093041ki

Synchronised cycling gene oscillations in presomitic mesoderm cells require cell-cell contact

Miguel Maroto, J. Kim Dale, Mary-Lee Dequéant, Anne-Cécile Petit and Olivier Pourquié Int. J. Dev. Biol. (2005) 49: 309-315

http://dx.doi.org/10.1387/ijdb.041958mm

\section{Diverse requirements for Notch signalling in mammals}

Duncan B Sparrow, Melanie Clements, Sarah L Withington, Annabelle N Scott, Jiri Novotny, David Sillence, Kenro Kusumi, Rosa S P Beddington and Sally L Dunwoodie

Int. J. Dev. Biol. (2002) 46: 365-374

http://dx.doi.org/10.1387/ijdb.12141422

5 yr ISI Impact Factor $(2011)=2.959$
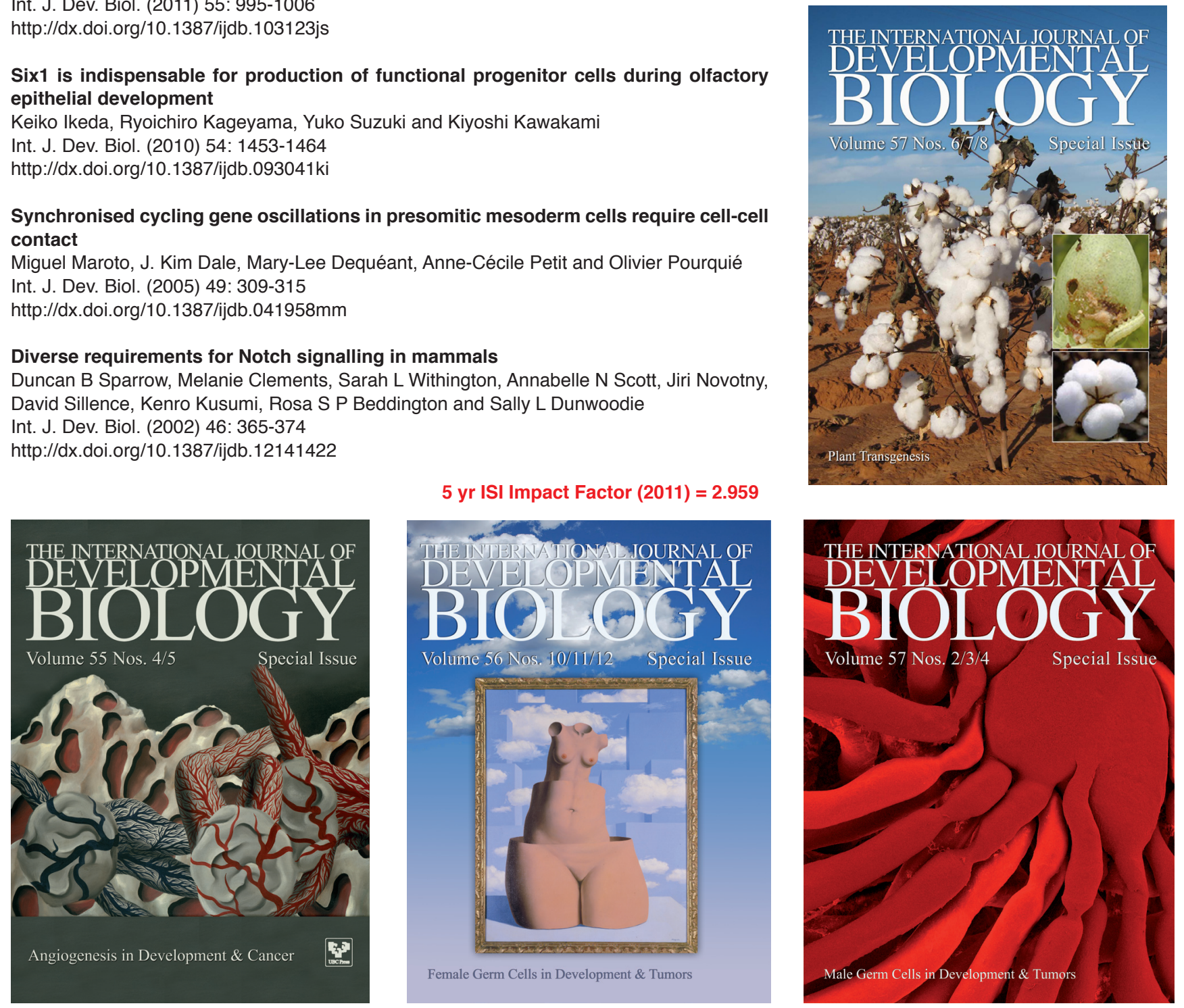